\title{
Research on the Fund-Raising Mechanism of China's Basic Pension System for Urban and Rural Residents
}

\author{
Chen Tianxiao \\ School of Management \\ Capital Normal University \\ Beijing, P. R. China, 100089 \\ (E-mail: cnuchen@163.com)
}

\begin{abstract}
In 2014, Chinese government merged the New Rural Social Pension (NRSP) program and the Social Pension for Urban Residents (SPUR) program and implemented a unified Basic Pension System for Urban and Rural Residents (BPSURR) scheme. Fund-raising is the key to the success of the BPSURR scheme. However, there are a lot of problems in the existing funding-raising mechanism. Based on introducing the existing fund-raising mechanism, this paper analyzed the status in quo and problems of the BPSURR scheme in fund-raising, elaborated the reasons for the problems, and finally put forward some countermeasures for perfecting the BPSURR's fund-raising mechanism. This paper concludes that the fund-raising mechanism of the BPSURR scheme can be improved as long as appropriate measures are taken.
\end{abstract}

Keywords-Basic Pension System for Urban and Rural Residents; Social Insurance; Fund-raising Mechanism, Population-aging

\section{INTRODUCTION}

China began to implement the New Rural Social Pension (NRSP) program in 2009 to cope with the accelerated aging of the rural population and began to implement the Social Pension for Urban Residents (SPUR) program in 2011 to provide social pension for urban residents who have no job. Since there was great similarity in the system design of the NRSP program and the SPUR program, and mainly since the insured persons who participated in the SPUR program was very few, the two social pension programs were simply made one when some local governments implemented the pilots of the two programs. In order to bridge the urban-rural economic divide and to promote balanced social development, on February 21, 2014, a file, the Opinions of the State Council on the Establishment of the Unified Basic Pension System for Urban and Rural Residents (BPSURR), was issued by Chinese central government. From then on, local governments at all levels who previously implemented respectively the pilots of the NRSP program and the SPUR program began to carry out a unified scheme, the BPSURR scheme.

Since the State of Council issued the Opinions on the Establishment of the Unified Basic Pension System for Urban and Rural Residents, many domestic scholars have been studying the BPSURR scheme. Wu Dan (2014) believed it has important significance and influence to establish a unified basic pension for urban and rural resident. Peng and Zhu's paper (2015) analyzed the backgrounds, innovations and prospects of the BPSURR scheme. Deng and Xian (2015) forecasted the problems in the implementation of the BPSURR and put forward some solutions to them. However, Huang Li's paper (2015) reviewed and evaluated the security level of the BPSURR scheme should be and concluded that the target replacement Rate of the BPSURR should be set to 50 percent of the average annual net income of rural residents. Certainly, there are still a lot of scholars (Gong Xunquan, 2011; KE Lihan et al.,2011; Huang Xiaochun, 2014; He Hui, 2014; Li Qiong and LiYeding, 2015; Wang and Tian, 2015) who, using the empirical method or investigation, studied the implementation of the BPSURR scheme in the specific area of China.

It is known to all that the fund-raising is the prerequisite for the smooth operation for any insurance system and it is also the key to implement smoothly the BPSURR scheme, so this paper aims at analyzing the fund-raising system of the BPSURR scheme. This paper will fist introduce the fund-raising system of the Opinions on the Establishment of the Unified Basic Pension System for Urban and Rural Residents, then analyze the problems and the causes of these problems in fund-raising when implementing the BPSURR scheme, and finally put forward some countermeasures for better raising funds for the BPSURR scheme.

\section{THE Fund-RAISING SYSTEM OF THE BPSURR SCHEME}

According the State Council's the Opinions on the Establishment of the Unified Basic Pension System for Urban and Rural Residents, the urban and rural residents, who are over 16 years of age (excluding students), non-staffs of state organs and institutions, and are not covered by the Basic Pension System for Enterprise Employees (BPSEE), can participate the BPSURR scheme in the household registration. The fund of the BPSURR scheme is composed of three parts, which are individual contributions, collective subsidies and government's subsidies. 


\section{A. Individual Contributions}

Persons who participate in the BPSURR Scheme shall pay the pension premiums in accordance with the provisions. The payment standard is currently set to 12 grades, which are respectively 100 yuan, 200 yuan, 300 yuan, 400 yuan, 500 yuan, 600 yuan, 700 yuan, 800 yuan, 900 yuan, 1000 yuan, 1500 yuan, and 2000 yuan per year. The people's governments of provinces, autonomous regions and municipalities can add payment grades according to the local actual situation, but the highest standard of payment grade is not allowed to exceed the annual payment amount of the flexible employees who participate in the BPSEE program. And the addition of payment grades by local governments should be reported to the Ministry of Human Resources and Social Security (HRSS) for record.

The Ministry of HRSS in conjunction with the Ministry of Finance is in charge of adjusting in a timely manner the payment grade standard, based on the situations such as the income growth of urban and rural residents. The insured persons self-determinedly choose the grade, pay more for much.

\section{B. Collective Subsidies}

The qualified village-level collective economic organizations shall grant subsidies to the insured persons for payment, and the subsidy standard shall be democratically determined by the villager assembly. It is encouraged for the qualified communities to put community welfare subsidies into the range of public welfare funds, and it is also encouraged for other social economic organizations, charitable organizations and individuals to provide grants for the insured persons' pension payment. However, the amount of subsidies and grants is not allowed to exceed the maximum grade of pension payment standard set by the local government.

\section{Government's Subsidies}

The government fully pays the basic pensions for all insured persons who are eligible for the pension-benefit conditions of the BPSURR scheme. The central finance is responsible for giving full subsidy for the central and western regions according to the standard of basic pension set by the central government, and 50 percent subsidy for the eastern region.

The local people's governments shall also subsidize the insured persons for pension payment. The subsidy standard should not be less than 30 yuan per person per year for those who select the lowest grade of the payment standard; the subsidy amount should be appropriately increased for those who select a higher grade of the payment standard; and the standard subsidy should not be less than 60 yuan per person per year for those who select the grades of and above 500 yuan of payment standard. The detailed subsidy standards and measures are determined by the people's governments of provinces, autonomous regions and municipalities. The local people's governments should pay part or all of the pension premiums of the minimum payment standard for disadvantaged groups to pay, such as the severe disabilities.
All of the individual contributions, the collective subsidies, the government's subsidies, and the grants for the insured persons provided by other social economic organizations, charitable organizations and individuals, are credited to individual accounts. The savings balance in the individual accounts accrues interests according to the state's provisions.

\section{The Status Quo and Problems OF FUND-RAISING OF THE BPSURR SCHEME}

Every year, the Ministry of HRSS of PRC, in general, releases on its website a statistics bulletin on Chinese human resources and social security of last year in the first half of year. In these statistics bulletins, the data can be found about the number of the insured persons, the number of pensioners, the fund income, and the fund expenditure of the BPSURR scheme in the previous years. However, since the NRSP program and the SPUR program respectively began to carry out in 2009 and 2011, and since the two programs were combined into the BPSURR scheme in 2014, the BPSURR statistics can only be available from 2012 to 2015. And since now is February, 2016 and the 2015 Statistics Bulletin On Human Resources and Social Security of China has not been released, the PBSURR statistics of the whole year of 2015 cannot be available, and only some data of its first three quarters can be available. Table 1 shows the number of the insured persons, the number of pensioners, the fund income, the fund expenditure, and the fund accumulated balance of the BPSURR scheme from 2012 to 2015 . The urbanization improves the roads, water conservancy, communications, energy and other infrastructure constructions of the rural areas.

Table1. Statistics of the BPSURR Scheme 2012-2015

Monetary Unit: hundred million RMB yuan Population Unit: ten thousand

\begin{tabular}{|c|c|c|c|c|c|}
\hline \multicolumn{2}{|c|}{ Year } & 2012 & 2013 & 2014 & $2015^{*}$ \\
\hline \multirow{2}{*}{ Numbers of the insured } & 48370 & 49750 & 50107 & 50266 \\
\hline \multirow{2}{*}{ Numbers of Pensioners } & 13075 & 13768 & 14313 & \\
\hline \multirow{2}{*}{ Fund Income } & Amount & 1829 & 2052 & 2310 & 2222.8 \\
\cline { 2 - 6 } & $\begin{array}{c}\text { Increase } \\
\text { Percentage }\end{array}$ & & $12.2 \%$ & $12.6 \%$ & \\
\hline \multirow{2}{*}{ Individual } & Amount & 594 & 636 & 666 & \\
\cline { 2 - 7 } Contributions & $\begin{array}{c}\text { Increase } \\
\text { Percentage }\end{array}$ & & $7.2 \%$ & $4.7 \%$ & \\
\hline \multirow{2}{*}{ Fund } & Amount & 1150 & 1348 & 1571 & 1650 \\
\cline { 2 - 7 } Expenditure & $\begin{array}{c}\text { Increase } \\
\text { Percentage }\end{array}$ & & $17.3 \%$ & $16.5 \%$ & \\
\hline \multirow{2}{*}{ Accumulated Balance } & 2302 & 3006 & 3845 & \\
\hline
\end{tabular}

*Note: the 2015 data are the ones of the first three quarters of 2015 Source: Sorted from the data on the website of the Ministry of Human Resources and Social Security 
Some features and problems of the fund-raising of the BPSURR scheme can be found from the Tablel above. It can be said that the fund-raising of the BPSURR scheme is facing a grim situation.

\section{A. The Numbers of the Insured Persons}

From the data of the Table 1 above, it can be known that the numbers of the insured persons of the BPSURR scheme have been increased from 483.70 million in 2012 to 502.66 million in the end of the third quarter of 2015. It is also known that the insured persons of the BPSURR scheme are mainly composed of the rural residents. However, according to the data of the Sixth National Census, the numbers of rural residents who are the age of 16 and above, which is the working age, are 512 million. That means there is not much room for increasing the fund-raising for the BPSURR by increasing the numbers of the insured persons.

\section{B. Fund Income and Individual Contributions}

From the data of the Table 1 above, it can be found that, the absolute scale of the fund income of the BPSURR seems to be very huge, however, the actual per capita of the fund income is very low. In 2014, for example, the absolute of scale of the fund income was 231.0 billion RMB yuan, but the per capita of it was only 461 RMB yuan. Furthermore, the growth rate of the fund income is not high, especially when compared with that of the fund expenditure. The growth rate of the fund income is lower than that of the fund expenditure nearly 4 percentage points.

Individual contributions should the bulk of the fund income of the BPSURR. However, in fact, the proportion of the individual contributions to the fund income is rather low, only slightly higher than a quarter. In 2014, the total fund income was 231.0 billion RMB yuan while the amount of individual contributions was 66.6 billion RMB yuan.

\section{The Numbers of Pensioners and Fund Expenditure}

In contrast to the slow growth of the number of the insured persons and the fund income, the numbers of pensioners and the fund expenditure of the BPSURR have been increasing rapidly. The numbers of pensioner increased from 130.75 million in 2012 to 143.13 million, with an annual increase of rough 7 million. And the amount of fund expenditure increased from 115.0 billion RMB yuan in 2012 to 157.1 billion RMB yuan, with an annual growth rate of 18.30 percent. Furthermore, with the acceleration of the population-aging in China, the increase in the numbers of pensioners and that in the fund expenditure will be faster, which will cause a great pressure for fund-raising of the BPSURR scheme.

Because the insured persons and the fund income have been increased slowly while the pensioners and the fund expenditure have been increased rapidly, the amount of the accumulated balance of the BPSURR is far from huge. In 2014, the per capita accumulated fund balance, averaged by the numbers of the insured persons, was only 767.36 RMB yuan.
In summary, it can be concluded that the fund-raising of the BPSURR is far from satisfactory, and the BPSURR scheme is facing a grim situation and is far from able to cope with the impendent challenge of population-aging.

\section{THE REASONS FOR THE DisSATISFACTION OF THE FUND-RASING OF THE BPSURR SCHEME}

From the analyses of Part 3 above, it can be known that the fund-raising of the BPSURR scheme is far from satisfactory. Then, what caused the dissatisfaction? At least, the following main factors did function.

\section{A. The BPSURR Scheme Lacks a Restrain Mechanism on the Government's Subsidies}

The State Council's the Opinions on the Establishment of the Unified Basic Pension System for Urban and Rural Residents really stipulates that the fund of the BPSURR scheme is composed of individual contributions, collective subsidies and government's subsidies. However, it does not make clear the restrain mechanism on the government's subsidies and does not make clear a growth mechanism for the government's subsidies.

A research (Li and Wang, 2015) shows that, the proportion of public finance for the BPSURR scheme to the local fiscal expenditure and the central fiscal expenditure is still very small while the absolute amount of public finance for the BPSURR scheme has been increased with the increase of the number of the insured persons. From 2010 to 2013, the proportions of local finance for the BPSURR scheme to the local fiscal expenditure were respectively 0.33 percent, 0.70 percent, 0.80 percent and 0.92 percent, and those of the central finance for the BPSURR scheme to the central fiscal expenditure were respectively 0.27 percent, 0.59 percent, 0.74 percent, and 0.78 percent.

\section{B. The BPSURR Scheme Lacks the Enterprises' Payment Mechanism of the BPSEE Program}

The BPSEE program requires that enterprise employees should pay monthly pension premiums with 8 percent of their wages and enterprises should also pay pension premiums for their employees according to 20 percent of the employees' wage. Furthermore, the enterprises' payment initially was credited to the employees' individual accounts. This kind of institutional arrangement not only ensures the stability of the pension premiums, but also enhances in a certain extent the enthusiasm of enterprises' employees to pay their pension premiums.

In contrast, the BPSURR scheme has not this kind of payment mechanism of enterprises' payment. The BPSURR scheme does have an analogous mechanism, the collective subsidies. According to the State Council's the Opinions on the Establishment of the Unified Basic Pension System for Urban and Rural Residents, the qualified village-level collective economic organizations shall grant subsidies to the insured persons for payment. However, this kind of provision is not mandatory, and there are no clear rules to ensure its execution. In fact, for the vast majority of villages 
in China, there is no the so-called qualified village-level collective economic organizations at all.

\section{The BPSURR Scheme Lacks an Strong Attraction to Most Rural Residents}

Rural residents are the main body of individual contributions of the BPSURR scheme. However, rural residents lack motivation to participate in the BPSURR scheme. Surveys found that many rural residents just selected the lowest grade of contribution to participate in and some young people even chose a variety of reasons for refusing to participate in it.

The reasons for the lack of enthusiasm are nothing more than the following. First, the rural residents in some regions are really very poor and have not much extra money to take part in the BPSURR scheme; second, the cognition of some rural residents is bounded and they pay more attention to the immediate interests than the future risks; third, some rural residents still have seriously the traditional concept of raising children as the guarantee against aging and do not pay attention to their own accumulation; fourth, some young people in the full vigor of life observe that it is rather far away for them to receive pensions and refuse to participate in the BPSURR scheme; fifth, the most important is that the pensions are too small and are beneath notice for some people.

\section{The Countermeasures for Augmenting the Fund- RAISING OF THE BPSURR SCHEME}

It is known from Part 3 above that the fund-raising of the BPSURR scheme is far from satisfactory and some reasons for the dissatisfaction have been found from the analysis of Part 4 above. Then what measures should be taken to enhance the level of fund-raising of the BPSURR scheme?

\section{A. Accelerating the Development of Rural Economy and Enhancing the Fund-Raising Capacity}

The ultimate approach to enhance the fund-raising of the BPSURR scheme is accelerating the development of the rural economy and narrowing the economic gap between urban and rural areas. In 2014, the per capita net income of rural residents was $10489 \mathrm{RMB}$ yuan while that of urban residents was $28844 \mathrm{RMB}$ yuan. There is a huge gap between them. Accelerating the development of rural economy not only can directly enhance the payment ability of rural residents, but also can increase the revenue of the government and indirectly enhance its subsidy ability to the BPSURR.

The following concrete measures can be taken to promote the development of rural economy: vigorously developing high-tech industries and improving the quality of economic development, speeding up the structure adjustment between urban and rural areas and promoting urbanization, speeding up transformation of agricultural development mode and constructing a modern system for agricultural production, developing service industry and improving the contribution of service industry to economic growth, and etc..

\section{B. Defining Fiscal Responsibility and Increasing the Strength of Governments' Subsidies}

Since the BPSURR scheme lacks the enterprises' contribution mechanism of the BPSEE program, the government should take the responsibility in the BPSURR scheme just as the enterprises do in the BPSEE program. The government should, in accordance with the financial capacity, gradually increase the residents' contribution subsidies, which not only can directly increase the fundraising of the BPSURR scheme, but also improve the attractiveness of the BPSURR to rural residents and indirectly increase its fund-raising.

\section{Improving the incentive mechanism of payment and arousing the individual potential to pay}

Individual contribution is the main source of the accumulative balance of individual accounts, so it is of great significance to guide rural residents to participate in the BPSURR scheme as soon as possible, long-termly, continuously. To encourage rural residents to pay pension premium, these measures as follows can be taken: (1) strengthening the propaganda and guiding rural residents to select a higher premium grade to contribute; (2) increasing 1 percent subsidy for their basic pension when the insured persons extend their payment period for every year after having paid for 15 years; (3) appropriately enhancing the interest rate for the accumulative balance of individual accounts; (4) elevating the capacity of service agencies and improving the service level to provide convenience for residents to pay pension premiums.

\section{Establishing a Normal Adjustment Mechanism for the Basic Pension}

The establishment of a normal adjustment mechanism for the basic pension has a great significance for improving the attractiveness of the BPSURR scheme. In February, 2014, the Ministry of HRSS and the Ministry of Finance issued a formal document which decided that, from July 1, 2014, the minimum standard of basic pension for urban and rural residents increased to $70 \mathrm{RMB}$ yuan per person every month, with the increase of $15 \mathrm{RMB}$ yuan per month based on the standard of $55 \mathrm{RMB}$ yuan per person every month. 70 RMB monthly, however, still has not extricated the pension from the expression of "pocket money". It is proposed to adjust the basic pension of the BPSURR scheme according to the rate of economic growth.

\section{E. Clearing the Rules of Collective Subsidy and Improving Collective Organizations' Responsibility}

The State Council's the Opinions on the Establishment of the Unified Basic Pension System for Urban and Rural Residents stipulated that the qualified village-level collective economic organizations shall grant subsidies to the insured persons for payment. However, there are no detailed provisions on how to understand "qualified". The 
detailed rules for the implementation of collective subsidy should be issued.

\section{Conclusions}

The BPSURR scheme has made some achievements since its implementation in 2014, but there also some problems, especially in fund-raising. Doing a good job in fund-raising has of great significance for implementing smoothly the BPSURR scheme. The fund-raising mechanism of the BPSURR scheme can be improved as long as appropriate measures are taken.

\section{REFERENCES}

[1] Ce Shen, J. B. Williamson. China's new rural pension scheme: can it be improved? www.Emeraldinsight.com/0144-333X.htm

[2] Deng Dasong, Xian Mihua. Problems and Countermeasures in the Implementation of the New Basic Pension System for Urban and Rural Residents [J]. Journal of Economic Aspect, 2015(9): 8-12(in Chinese)

[3] He Hui. Risk Assessment of Individual Contribution Ability of the Urban and Rural Residents'Social Old-Age Insurance [J].Journal of Xiangtan University (Philosophy and Social Science), 20014(38): 4853(in Chinese)

[4] Huang Li. Review and Evaluation on Rural-urban Residents Social Pension Insurance: Based on Replacement Rate of Basic Pension Insurance [J]. Population and Economics, 2015(5): 91-99(in Chinese)

[5] Li Qiong, Yao Wenlong. The perfection of the basic old-age insurance system for urban and rural residents in China ---- Experience based on Chile mode [J].Technological Development of Enterprise, 2015(9): 4547(in Chinese)

[6] Peng Yin, Zhu Junsheng. Establishing a Unified Basic Pension Insurance System for Urban and Rural Residents: Backgrounds, Innovations and Prospects [J]. Scientific Research on Aging, 2015(1.3): 29-38(in Chinese)

[7] Wang Hui, Li Qiong. On Financing Model of Urban and Rural Residents' Basic Pension Insurance System and its Realistic Choice [J]. Journal of Hunan University of Commerce, 2015(22): 89-92(in Chinese)

[8] Zhu Lili, Chu Fuling. A Study on the Establishment of the Financing Growth Mechanisms Targeting Basic Living Standard Security for the Urban and Rural Residents Basic Pension Insurance [J].Contemporary Economic Management, 2016(38): 80-86 (in Chinese) 